\title{
O Ensino de Ciências no contexto da Educação Infantil: tecendo estratégias lúdicas
}

\section{para abordar o tema coronavírus}

\author{
Science Teaching in the context of Early Childhood Education: weaving playful strategies to \\ address the coronavirus theme
}

Enseñanza de las Ciencias en el contexto de la Educación de la Primera Infancia: tejiendo estrategias lúdicas para abordar el tema del coronavirus

\author{
Paola Sturza Brum Just \\ ORCID: https://orcid.org/0000-0002-1833-5517 \\ Instituto Federal Farroupilha, Brasil \\ E-mail: paolasturza@gmail.com \\ Fernanda Monteiro Rigue \\ ORCID: https://orcid.org/0000-0003-2403-7513 \\ Universidade Federal de Uberlândia, Brasil \\ E-mail: fernanda_rigue@ hotmail.com \\ Alice Copetti Dalmaso \\ ORCID: https://orcid.org/0000-0002-4447-0958 \\ Universidade Federal de Santa Maria, Brasil \\ E-mail: alicedalmaso@gmail.com
}

\begin{abstract}
Resumo
O presente trabalho emerge com o objetivo de apresentar a construção de estratégias colaborativas envolvendo o Ensino de Ciências com crianças no retorno escolar presencial, marcado pela readaptação curricular em tempos pandêmicos da COVID-19. É motivado pelo interesse em desenvolver questões que envolvam a temática de educação sanitária, como cuidados com a higiene. O viés metodológico dessa pesquisa é de abordagem qualitativa, de natureza aplicada e do tipo Pesquisa-ação. Por meio da pesquisa, foi possível pensar estratégias lúdicas e experimentações para desenvolver iniciativas pedagógicas com os principais envolvidos, as crianças, instigando a curiosidade, a intervenção, os apontamentos, os diálogos e as percepções das mesmas, salientando a importância da escuta atenta ouvindo suas perguntas-máquinas. Desse modo, com o estudo, foi possível aguçar as narrações das crianças, afinando um corpo presente e atento para com suas noções quanto ao coronavírus, com vistas a produzir possibilidades de exploração pedagógica.
\end{abstract}

Palavras-chave: Educação infantil; Ensino de ciências; COVID-19.

\begin{abstract}
The present work emerges with the objective of presenting the construction of collaborative strategies involving Science Teaching with children in the face-to-face school return, marked by curriculum readaptation in COVID-19 pandemic times. It is motivated by the interest in developing issues involving the theme of health education, such as hygiene care. The methodological bias of this research is of a qualitative approach, of an applied nature and of the Action-Research type. Through the research, it was possible to think of playful strategies and experiments to develop pedagogical initiatives with the main stakeholders, the children, instigating curiosity, intervention, notes, dialogues and their perceptions, emphasizing the importance of attentive listening, listening to their machine questions. Thus, with the study, it was possible to sharpen the children's narratives, tuning a present and attentive body to their notions about the coronavirus, with a view to producing possibilities for pedagogical exploration.
\end{abstract}

Keywords: Child education; Science teaching; COVID-19.

\section{Resumen}

El presente trabajo surge con el objetivo de presentar la construcción de estrategias colaborativas que involucren la Enseñanza de las Ciencias con los niños en el regreso presencial a la escuela, marcado por la readaptación curricular en tiempos de pandemia de COVID-19. Está motivado por el interés en desarrollar temas que involucren el tema de la educación para la salud, como el cuidado de la higiene. El sesgo metodológico de esta investigación es de enfoque cualitativo, de carácter aplicado y del tipo Investigación-Acción. A través de la investigación, fue posible pensar en estrategias lúdicas y experimentos para desarrollar iniciativas pedagógicas con los principales actores, los niños, incitando la curiosidad, la intervención, las notas, los diálogos y sus percepciones, enfatizando la importancia de la escucha atenta, escuchando sus preguntas de máquina. Así, con el estudio se logró agudizar las narrativas de los niños, 
sintonizando un cuerpo presente y atento a sus nociones sobre el coronavirus, con miras a generar posibilidades de exploración pedagógica.

Palabras clave: Educación infantil; Enseñanza de las ciencias; COVID-19.

\section{Introdução}

Este estudo toma corpo com base em um processo de tensionamento e problematização de algumas ações que foram planejadas e também implementadas no contexto da etapa da Educação Infantil de uma instituição de ensino situada em um município do interior do Estado do Rio Grande do Sul (RS). Ações estas que mobilizaram o corpo docente e também as crianças pequenas da escola, interessadas em compreender como seria possível construir subsídios interessantes e potentes para o retorno presencial da educação escolar, a partir dos conhecimentos inerentes a área das Ciências da Natureza.

Por intermédio de diálogo informal com as docentes de turmas da Pré escola da escola, pode-se verificar em suas narrativas que as mesmas mostravam-se inseguras quanto ao retorno presencial das atividades educativas. Segundo apontavam, manifestavam se sentir com medo devido ao retorno presencial das aulas com as crianças, depois de um longo tempo dedicado ao ensino remoto. Externalizavam ter muito receio quanto à segurança sanitária das crianças e delas próprias, justamente por ainda estarmos em contato com a pandemia de COVID-19¹.

A equipe escolar do referido território encontrava-se em meio a um dilema de como seria desenvolvido o acolhimento destas crianças. A compreensão e aceitação das normas de biossegurança, utilização de máscaras, distanciamento social, uso de equipamentos de proteção individual pelos docentes que as atenderiam, como aconteceria o processo sem que houvesse a 'robotização' destas crianças, eram temáticas e elementos que preocupavam a equipe diretiva da instituição. As educadoras sinalizavam o interesse de poderem se sentir seguras e à vontade mesmo com essas limitações, porém, estavam mobilizadas a criar uma recepção que não produzisse afetos tristes nas crianças, que não interferissem, sobremaneira, nos possíveis processos de aprendizagem.

Notando a emergência de tal situação atípica e problemática na escola, visualizamos a potência de operar com o Ensino de Ciências da Natureza para compartilhar e auxiliar neste processo, já que o mesmo permite a investigação e o estudo de hábitos cotidianos, incluindo o conhecimento relativo ao funcionamento de um vírus, bem como questões que envolvam a temática de educação sanitária, como cuidados com a higiene. Portanto, de modo colaborativo, buscou-se construir estratégias e ações para trabalhar interdisciplinarmente, aliando o Ensino de Ciências da Natureza aos conhecimentos pedagógicos específicos relativos ao desenvolvimento infantil, os quais buscam afetar significativamente a qualidade dos processos de aprendizagem na infância.

As crianças encontram-se em fases do desenvolvimento que lhes permitem não somente interpretar o mundo, mas criar e produzir suas próprias ideias e concepções sobre ele. Desta forma, objetivou-se trabalhar questões de higiene pessoal na etapa infantil, sabendo da potência das crianças vivenciarem estas questões, tornando o conhecimento científico algo presente ao longo da sua vida. Nesse sentido, buscou-se também investir na ludicidade com as crianças, garantindo que a potência da imaginação da Educação Infantil não fosse ameaçada neste contexto pandêmico, trazendo uma abordagem minimamente sensível e cuidadosa com as mesmas, trabalhando o assunto do coronavírus, da pandemia, do distanciamento social e das práticas de cuidado de si e do outro, fomentando hábitos de higiene.

Objetivou-se com tal proposta construir possíveis estratégias envolvendo o Ensino de Ciências da Natureza com crianças no retorno escolar presencial, marcado pela readaptação curricular em tempos pandêmicos da COVID-19. Procurou-se proporcionar um espaço de escuta e acolhimento nas situações educacionais ${ }^{2}$ produzidas junto das crianças, de modo que elas

\footnotetext{
${ }^{1}$ Trata-se de uma infecção respiratória aguda causada pelo coronavírus SARS-CoV-2.

${ }^{2}$ Movimento que aciona “[...] encontrar a atenção que se aviva para essa emergência, para então produzir novos começos: eis o que pode ser um chamado em educação" (Dalmaso \& Rigue, 2021, p. 2).
} 
pudessem se sentir seguras e acolhidas em verbalizar os sentimentos pessoais vivenciados nesse processo de enfrentamento da pandemia, compartilhando suas vivências durante período em que estavam afastadas do ambiente escolar, conversando sobre o coronavírus através da experimentação, imaginação e do acolhimento da pergunta-criança (Dalmaso, Oliveira \& Corrêa, 2018).

Para tanto, nas linhas a seguir é exposta uma breve revisão de literatura envolvendo o viés teórico que inspirou o presente estudo. Em seguida, serão apresentados os procedimentos metodológicos que delineiam o desenvolvimento da escrita e da pesquisa, seguidos pela análise e discussão dos dados e resultados, e das considerações finais.

\section{Revisão da Literatura}

$\mathrm{Na}$ escrita que designa os seis direitos de aprendizagem e desenvolvimentos na Educação Infantil, defendidos na Base Nacional Comum Curricular (Brasil, 2018), verifica-se os verbos conviver, brincar, participar, explorar, expressar e conhecerse, os quais não podem estar livres das intenções das educadoras e educadores os quais criarão práticas pedagógicas a partir desses direitos e desenvolvimentos. Assim, o arquivo da BNCC sinaliza o seguinte:

Essa intencionalidade consiste na organização e proposição, pelo educador, de experiências que permitam às crianças conhecer a si e ao outro e de conhecer e compreender as relações com a natureza, com a cultura e com a produção científica, que se traduzem nas práticas de cuidados pessoais (alimentar-se, vestir-se, higienizar-se), nas brincadeiras, nas experimentações com materiais variados, na aproximação com a literatura e no encontro com as pessoas (Brasil, 2018, p. 39).

Essas práticas, afirmadas e promulgadas nas linhas supracitadas, como parte do processo de organização e planejamento de um educador/a - Pedagogo/a - em situações educacionais com crianças, auxilia na garantia de promoção de uma infinidade de experiências corporais e cognitivas a serem vivenciadas com as mesmas, objetivando uma noção de desenvolvimento pleno. Nesse tom, corroboramos que o referido cenário expande o que batizamos como proposições e aproximações iniciais (e necessárias) de introdução e aproximação de uma fundamentação científica na área das Ciências da Natureza na Educação Infantil.

Vale ressaltar que "O Ensino de Ciências para crianças tem como ator direto o professor [...] formado em Pedagogia" (Rigue, Amestoy \& Corrêa, 2019, p. 9). Levando isso em conta, o estudo desenvolvido por Rigue, Amestoy e Corrêa aponta para uma preocupação quanto à formação inicial pouco potente dos/as discentes em Pedagogia, no que tange ao estudo e reflexão do campo complexo que é a educação em Ciências ${ }^{3}$ tanto para a Educação Infantil quanto para os Anos Iniciais. Conforme escrevem "Há uma desconexão entre os conceitos pertinentes ao Ensino de Ciências Naturais e a formação de professores [...], o que tem acarretado em um grande número de licenciados e também Pedagogos formados que, não compreendem e refletem sobre os saberes da área" (Rigue, Amestoy \& Corrêa, 2019, p. 5).

Fato que é justificado "[...] no sentido que na maioria das vezes não é desenvolvido um aprofundamento teórico conceitual nos conceitos da área [...]" (Rigue, Amestoy \& Corrêa, 2019, p. 5), o que, por sua vez, corrobora para uma mobilização de saberes (na Educação Infantil e/ou nos Anos Iniciais) que acaba por ficar restrita às aprendizagens que esses/as docentes tiverem em sua formação escolar durante a Educação Básica. Essa constatação corrobora com a necessidade de direcionar esforços para qualificar potencialmente o trato com os conceitos e ênfases do Ensino de Ciências no que tange os cursos de licenciatura, para que esses profissionais possam desenvolver suas ações na Educação Infantil, ampliando, se

\footnotetext{
${ }^{3}$ Vale ressaltar que "A formação em ciências do Pedagogo, por sua vez, tem como ator direto o Licenciado em uma das áreas das Ciências Naturais, a saber: Química, Física ou Biologia. Desse modo, o que uma criança recebe como atividade de Ensino de Ciências depende da formação de profissionais da Pedagogia e essa depende da formação do formador de educadores em uma das áreas das Ciências Naturais (na sua quase totalidade formada em Biologia, em virtude de que boa parte dos concursos para docente em ciências exige formação em Biologia). Logo, o que uma criança recebe em sala de aula (por parte do Pedagogo) é dependente da qualidade e do acontecimento dessas duas instâncias de formação de professores" (Rigue, Amestoy \& Corrêa, 2019, p. 9).
} 
possível, o repertório de práticas educativas com crianças.

Os fenômenos da natureza quando problematizados nas ciências, acompanham o processo de descoberta da criança. A disciplina, em sua produção identitária, não se preocupa em estabelecer esse percurso na formação da criança, objetivando questões que não podem ser singularizadas e, na maioria das vezes, podando as sensações envolvidas no aprender. O lugar que o professor ocupa na escola é desafiador. A busca por estratégias educacionais precisa ultrapassar a imobilização do corpo e da mente. Ela precisa estar atrelada a não quantificação do que foi aprendido pelo estudante, mas sim direcionada para os movimentos que o aprendente faz quando é convidado a pensar ciências (Rigue et al., p. 14).

Nesse sentido, consideramos importante que quando nos encontramos com as crianças, ao abordar e propor diferentes situações educacionais - envolvendo cuidados e práticas que envolvam conhecimento científico - consideremos que as crianças estão imbricadas numa rede a qual diz de seus traços, códigos culturais, linguísticos, pertencentes ao seu grupo social.

O ser humano, sujeito de sua aprendizagem, nasce em um ambiente mediado por outros seres humanos, pela natureza e por artefatos materiais e sociais. Aprende nas relações com esse ambiente, construindo tanto linguagens quanto explicações e conceitos, que variam ao longo da sua vida, como resultado dos tipos de relações e de sua constituição orgânica (Delizoicov et al, 2011, p. 130).

Enquanto educadores e educadoras, então, passamos a atentar a gestos que movimentam em perceber as vozes constitutivas das vidas infantis com as quais nos encontramos, ouvindo e sobretudo abertos a estudar suas realidades, suas percepções prévias, sua cultura primeira (Delizoicov et al, 2011), e suas emoções, as quais se produzem fora de situações organizadas de ensino (Dalmaso et al, 2018).

Nesse sentido, o convite à produção de perguntas direcionadas às crianças, ou por elas produzidas - instaurando narrativas plurais na conversação com as mesmas (Dalmaso et al, 2018; Dalmaso et al, 2020) é levado em conta, posto que acreditamos que é:

[...] o viver no conversar que constitui o humano. Acreditamos também que o humano surge, de fato, quando o conviver no conversar, como um modo de vida que se conserva geração após geração na aprendizagem das crianças, passa a definir a linhagem da qual somos agora o presente (Maturana \&Verden-Zoller, 2004, p. 135).

O que corrobora e amplia a potência da $\operatorname{BNCC}(2018$, p. 42) ao tratar das especificidades da infância, afirmando a importância:

[...] de promover experiências nas quais as crianças possam falar e ouvir, potencializando sua participação na cultura oral, pois é na escuta de histórias, na participação em conversas, nas descrições, nas narrativas elaboradas individualmente ou em grupo e nas implicações com as múltiplas linguagens que a criança se constitui ativamente como sujeito singular e pertencente a um grupo social.

Nessa linha de pensamento, entendemos que vivenciar experiências ricas e significativas na Educação Infantil precisa ser promovida e comprometida por processos educacionais que instauram gestos de cuidado e atenção ${ }^{4}$ (Dalmaso \& Rigue, 2020), “[...] implicados pela nossa presença” (Josso, 2004, p. 73). Trata-se de produzir encontros ${ }^{5}$ com as crianças que não somente pelas vias do controle, autoridade e obediência, da negação de seu ser, sua existência e potência, mas onde o fluir da vida, relacional e interativa, produz um acontecimento-tempo que instaura linguagens, emoções e brincadeiras baseadas em

\footnotetext{
4 “[...] consideramos uma postura-corpo atencional que desejamos aqui insuflar em nossas concepções educacionais, não para encontrar supostas respostas ao que entendemos por insuficiências pedagógicas, mas para, sobretudo, inventar palavras, imaginar mundos, angariar tons menores no demasiadamente mortificado em educação, a partir de novos sentidos intensivos produzidos nesse território" (Dalmaso \& Rigue, 2021, p. 8).

5 “[...] a potência da liberdade nos processos educacionais. Processos que dissolvem a aposta em prescrições apriorísticas e comprometem-se com a ética pulsional do encontro dos corpos e, portanto, daquilo que se aprende com eles, em meio a eles, nas relações entre os humanos que inauguram encontros, bons encontros, multidões" (Rigue, 2021, p. 25).
} 
experiências que envolvam auto-respeito, e dignidade da confiança e aceitação mútua nas relações que circundam as crianças (Maturana \& Verden-Zoller, 2004).

\section{Metodologia}

A metodologia dessa pesquisa possui abordagem qualitativa (Goldenberg, 1997), com natureza aplicada e do tipo Pesquisa-ação (Tripp, 2005). Como escreve Tripp (2005) “A pesquisa-ação educacional é principalmente uma estratégia para o desenvolvimento de professores e pesquisadores de modo que eles possam utilizar suas pesquisas para aprimorar seu ensino" (p. 445). Ademais, demanda intervenções na prática, já que é participativa e colaborativa, surgindo a partir de uma problemática relevante e emergente. Assim, o estudo discorre acerca dos achados decorrentes de um movimento direcionado às crianças, buscando explanar reflexões sobre a importância da inserção do tema Coronavírus na Educação Infantil, trabalhando questões que incentivem a curiosidade, o desenvolvimento e o pensamento crítico juntamente com a iniciação científica.

Buscamos desenvolver a curiosidade nas crianças, instigando o interesse pelo aprendizado e os cuidados quanto ao contágio e propagação do Coronavírus. Concomitantemente, atentamos em buscar resultados significativos no desempenho emocional-relacional destas crianças e no desenvolvimento da proposta de trabalho sobre a importância da higiene em tempos de pandemia, bem como alavancar questões de subsídio para discutirmos pontos que consideramos fundamentais na conversação com as crianças, a saber: o que é o Coronavírus, quais os cuidados que devemos apresentar com relação à pandemia, o que esse vírus causa, como ocorre o contágio, dentre outros pontos que surgiram no decorrer da conversação.

É importante pontuar que, de acordo com a Base Nacional Comum Curricular da Educação Infantil (BNCC, 2018), arquivo que embasa as experiências a serem desenvolvidas na etapa da Educação Infantil, nós não temos componentes curriculares, mas Campos de Experiências, os quais se tratam dos saberes e conhecimentos fundamentais a serem ofertados e promovidos às crianças e associados às experiências vividas no ambiente escolar. Dessa maneira, organizamos as situações com as crianças apenas direcionando o conhecimento científico, relacionando-o à temática do Coronavírus voltado à Educação Infantil, visando a compreensão das situações sanitárias e também de convívio e entendimento pandêmico.

Desta forma, pensamos e construímos juntos possibilidades sobre o então, amedrontador assunto, que assombrava a equipe escolar: o retorno presencial das crianças ao ambiente escolar. Desejávamos que esse retorno se desse mesmo de modo acolhedor, porém vivo e potente, pensando estratégias experimentais ${ }^{6}$ e lúdicas para receber os principais envolvidos nesta nova situação, as crianças. Nossa tarefa residia, sobretudo, em instigar a curiosidade, porém intervindo com apontamentos, valorizando possíveis diálogos, abrangendo possibilidades de atravessamentos outros e agregando as percepções das crianças através de uma escuta atenta e interessada às perguntas-máquinas (Deleuze \& Guattari, 1997) mobilizadoras de um pensarviver que é próprio da criança (Dalmaso, Oliveira \& Corrêa, 2018).

Por último, é importante salientar que foram realizados registros dos encontros produzidos com as crianças nas escolas. As imagens registradas foram manipuladas a fim de assegurar o anonimato das identidades infantis, e movimentadas neste texto a fim de ilustrar algumas das experimentações-encontros produzidos com as crianças.

\section{Resultados e Discussão}

Para lançarmos o tema coronavírus para as crianças da pré-escola (Pré B) da Escola Municipal de Educação Infantil, utilizamos uma réplica do vírus produzida em tamanho aumentado e confeccionada com EVA. A partir desse material didático, procuramos visualizar quais eram os conhecimentos prévios das crianças quanto à questão pandêmica que produzida

\footnotetext{
6 "Num caminhar variável e leve, a experimentação corresponde ao comungar e à variação do hábito, cultivo de uma prática atencional" (Dalmaso \& Rigue, 2021, p. 10).
} 
desconforto e incerteza não somente nos ambientes educacionais, como também no âmbito social, familiar, midiático, atingindo dimensões socioemocionais e psíquicas dos indivíduos.

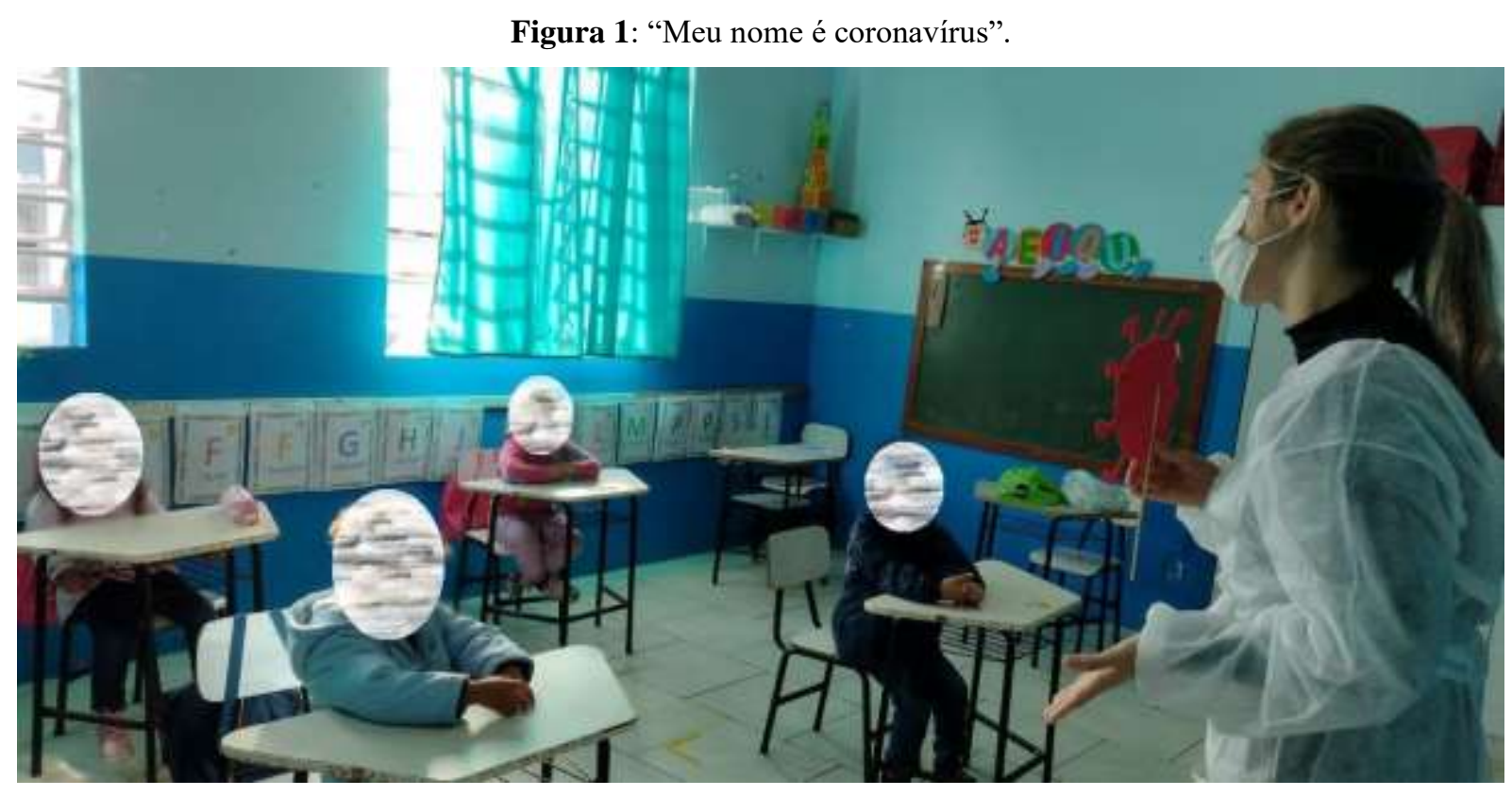

Fonte: Imagem do acervo das pesquisadoras (2021).

Para iniciar a conversação com as crianças utilizamos algumas questões norteadoras, a saber: Qual a diferença que vocês notaram na vida de vocês, antes do coronavírus, e agora, quando retornaram à escola? O que vocês sabem sobre o Coronavírus? Os pais de vocês conversaram sobre o Coronavírus, COVID-19 ou pandemia? Como vocês se sentiram durante este tempo que ficaram fora da escola e sem poder sair por conta do Coronavírus? Na televisão vocês ouviram falar alguma coisa sobre o Coronavírus?

Na conversação, com relação às diferenças relatadas pelas crianças de como eles percebiam a escola antes e depois do coronavírus, as crianças afirmaram sobre a presença das máscaras, do álcool em gel, das roupas de proteção das professoras e observaram ter poucos coleguinhas na sala de aula, uma realidade bem diferente da que presenciaram anteriormente, já que ambos frequentavam a escola desde o berçário e maternal. Já em relação a como eles se sentiam, relataram estar tristes por não poderem sair no portão, ou não ter escola, não brincar com os amigos, não poder acompanhar a mãe no mercado, ficar alguns dias longe dos avós, dentre outras narrativas envolvendo a rotina que viviam antes da situação da pandemia modificando suas rotinas e vidas.

Nas respostas relacionadas à fala dos pais, argumentaram: "Eles falaram que não poderiam sair, que tinha que usar máscara e álcool em gel”; "Minha mãe falou que não dá mais pra eu ir no mercado com ela”; “Tem que usar máscara e álcool em gel". Estas falas demonstram os cuidados pontuais, envolvendo os protocolos de higiene com o corpo e distanciamento social, o qual a maioria de nós teve que relembrar ou efetivamente aprender ${ }^{7}$ com a presença do vírus. Nesse sentido, foi possível perceber que eles relacionavam o coronavírus ao uso de máscara e álcool em gel, mas quando questionados o porquê de terem de usar a máscara e o álcool em gel, relataram que era porque os pais os orientaram a fazer isso, denotando que o conhecimento científico relacionado a esses comportamentos talvez não tivesse sido o foco em explicações orientadas às crianças.

Quanto aos fatos na televisão, as crianças afirmaram não lembrar, que não tinham visto nada acerca do tema,

\footnotetext{
7 “Aprender não é reproduzir, mas inaugurar (...)” (Schérer, 2005, p. 1188).
} 
demonstrando que o assunto na televisão não chamou tanto a atenção deles, por diversas variáveis possíveis que não nos cabe aqui discorrer. Notamos que eles entendiam o uso da máscara como um comando/ordem, não associando com a real necessidade do seu uso, o que nos fez intervir com uma explicação: a máscara era necessária para se proteger e proteger o amigo ao lado, por isso ela tem de cobrir a boca e o nariz, porque caso a gente espirre, tussa ou mesmo fale, impedimos que nossa saliva ou a secreção que saia do nariz, espalhe as gotinhas bem pequenas, muito pequenas mesmo, pelo ar. Elas são invisíveis aos nossos olhos, porém, é dentro destas gotículas que ficam os vírus, o coronavírus, caso a gente esteja doente. Se tossirmos ou expirrarmos ou falarmos, essas gotinhas se propagam por diferentes lugares do ambiente, podendo pegar na classe, na mãozinha de vocês, na garrafinha de água e daí quando você pega nestes locais e leva na boca, no nariz ou nos olhos, a pessoa que não estava com o vírus vai ficar com eles. Isso se chama contágio, é quando o coronavírus consegue invadir nosso sistema imune. Também a máscara serve como barreira para a gente não transmitir, caso tenha o coronavírus, e para também não pegar quando manipulamos ou levamos a mão até a boca ou nariz. As professoras utilizam protetores faciais, aqueles que parecem de um astronauta, para quando forem trabalhar pertinho de vocês protegerem os olhinhos dela e a integridade de vocês também.

Sobre o entendimento que tinham a respeito do coronavírus, falaram que o mesmo deixava as pessoas muito doentes e que fazia um "estrago" dentro delas. Uma das meninas associou a forma do coronavírus com uma mamona: "Esses dias eu peguei um coronavírus, lá fora, no campo onde eu fui com o meu pai, ele era verdinho e tinha pontinhas como este".

Na sequência, a educadora responsável pela prática com as crianças - uma das autoras deste texto - se aproximou e procurou entender sobre o que ela estava falando, percebendo que se tratava de um fruto da espécie Ricinus communis (popularmente conhecido como mamona). Fato que a deixou encantada, em perceber a imaginação e rápida facilidade associativa à memória da criança, ao relacionar a forma microscópica do vírus com o fruto dessa planta, a partir de um passeio rotineiro vivenciado por ela.

Logo após esse primeiro momento, iniciou-se a leitura de uma história interativa sugerida pela pedagoga, responsável pela turma: "Meu nome é coronavírus" (Cruz, 2020). Com a história, conseguimos explorar vários aspectos relacionados aos cuidados com relação à propagação do vírus, e quais eram os sintomas causados pelo mesmo. Partimos da premissa de explicar que este vírus era 'primo' da gripe e do resfriado, perguntando às crianças, então, se algum deles já havia ficado resfriado e como eles haviam se sentido ao ficarem doentes. As crianças responderam que, quando gripadas, ficavam sem vontade de brincar, às vezes com nariz escorrendo e também com tosse. Assim, falamos que o coronavírus era, em certo ponto, semelhante, só que um pouco mais grave, como se fossem estes os mesmos sintomas, porém de uma forma mais agravada, e que muitas pessoas poderiam ir para o hospital por causa dele.

\subsection{Meu nome é coronavírus}

Logo após esse primeiro momento, iniciou-se a leitura de uma história interativa sugerida pela pedagoga, responsável pela turma: "Meu nome é coronavírus" (Cruz, 2020). Com a história, conseguimos explorar vários aspectos relacionados aos cuidados com relação à propagação do vírus, e quais eram os sintomas causados pelo mesmo. Partimos da premissa de explicar que este vírus era 'primo' da gripe e do resfriado, perguntando às crianças, então, se algum deles já havia ficado resfriado e como eles haviam se sentido ao ficarem doentes. As crianças responderam que, quando gripadas, ficavam sem vontade de brincar, às vezes com nariz escorrendo e também com tosse. Assim, falamos que o coronavírus era, em certo ponto, semelhante, só que um pouco mais grave, como se fossem estes os mesmos sintomas, porém de uma forma mais agravada, e que muitas pessoas poderiam ir para o hospital por causa dele.

Em seguida, perguntamos como eles se sentiam ao escutar a palavra coronavírus. Para orientá-los, ilustramos as emoções com emojis, com faces que designavam um rosto tranquilo, confuso, preocupado, curioso, nervoso e triste, para que, 
então, eles escolhessem qual das expressões os representava quando falavam sobre o assunto, o que eles sentiam com elas. Duas crianças se identificaram com o emoji de confuso, uma com o de curioso e outra com o de nervosa. Como um movimento de aproximação e validação de suas emoç̃oes (Siegel \& Bryson, 2015), relatamos que, por vezes, também nos sentimos assim, mas também procuramos tranquilizá-los, afirmando que aos poucos as coisas iriam melhorar, ainda que tivéssemos que seguir tomando os cuidados necessários de distanciamento, higiene e proteção.

A história contada às crianças mostrava uma narrativa onde os adultos se preocupavam com o que aparecia na televisão, mas que o próprio coronavírus iria explicar quem ele era: quando ele visitava o corpo humano, trazia consigo falta de ar, febre, tosse, dor de cabeça, dor de barriga. Nesse momento, salientamos que comunicassem a seus pais ou responsáveis quando se sentissem assim, evitando de ir à escola quando estivessem com os sintomas citados, para não passar para os outros coleguinhas. Explanamos que logo o vírus vai embora do corpo e que a grande maioria das pessoas se sentem melhor em alguns dias. Produzimos analogias, explicando que esse processo era parecido como quando nosso joelho sara depois de um arranhão, mas que, apesar de tudo, eles poderiam ficar tranquilos, pois os adultos que cuidam de vocês vão mantê-los seguros. Quanto a eles, o que poderia ajudar era continuar lavando as mãos frequentemente com água e sabão.

Logo em seguida, os estudantes foram convidados a se levantarem e ficarem em pé ao lado de suas classes para que dançássemos suas músicas preferidas enquanto fazíamos movimentos representativos de lavar as mãos. Eles deveriam passar álcool em gel em suas mãos e contar até 10 para que durante este tempo o álcool secasse. Foi assim que passamos nas mãos de todos o álcool em gel enquanto contávamos até 10, acompanhando os algarismos numéricos expostos na sala de aula das crianças e apontando a numeração correspondente.

Por fim, a história contada abordava a ideia de que se a criança seguisse estes cuidados, o coronavírus "não iria visitálos". Enquanto isso, estariam os doutores e cientistas desenvolvendo vacinas que permitissem às pessoas se cumprimentarem sem ficarem doentes. Salientando a importância da vacinação, relatando que as professoras e funcionários da escola estavam todos vacinados e que, apesar da picadinha, era um momento de muita esperança, incitamos as crianças a contarem isso para os seus pais, para que, quando chegasse a sua vez de se vacinar, todos fizessem as duas doses da vacina, para que tudo pudesse voltar ao normal.

Com a história foi possível que houvesse uma apresentação contextualizada do tema que seria desenvolvido nos momentos seguintes, dando forma a um movimento amistoso que gerou um certo conforto para a fala dos pequenos, bem como aproximação e familiaridade das crianças com as pesquisadoras, agregando fluidez às perguntas que surgiram na sequência.

Nesse sentido, no decorrer da proposta, incentivamos as crianças a perguntarem o que mais elas gostariam de saber. Foi assim que surgiram perguntas do tipo: "Do que o coronavírus se alimenta? Como nasce o coronavírus bebê? Ele toma um leite especial? O que são as árvores que estão dentro do pulmão da história? Se eu levar a mão no meu nariz, eu pego coronavírus? O coronavírus veio de avião?”. Percebe-se aí a potência das perguntas-crianças, movimentadoras de um pensar que é próprio das circunstâncias sociais e emocionais as quais elas vivem, mas também de um devir-cognitivo das mesmas (Kastrup, 2000). Afinal, quem faz esse tipo de perguntas, as quais nós nunca temos respostas prontas para elas? Assim, foi nesse sentido que, com estas perguntas promovidas por eles suscitadas após a leitura, é que estruturamos as proposições seguintes, as quais serão a seguir apresentadas.

\subsection{Experimentação com Glitter}

No movimento seguinte, e por iniciativa da pedagoga regente da turma, decidimos por inserir uma atividade a qual as crianças confeccionassem o desenho da estrutura do coronavírus, preenchendo e colando bolinhas de papel crepom, promovendo o desenvolvimento de habilidades importantes na Educação Infantil, como a coordenação motora fina, concentração, criatividade e a percepção visual. 
Além disso, ao vislumbrar os questionamentos lançados pelas crianças em momento anterior, pensamos sem seguir apresentando de forma lúdica a propagação do vírus no ambiente. Desse modo, resolvemos utilizar glitter, de diferentes cores, para produzir uma encenação com o material, aludindo à propagação do vírus. A professora, então, dramatizou um espirro e neste momento, colocou a mão no glitter, em seguida começou a tocar nas coisas com a mão carregada de glitter, o qual se espalhava pela classe, pelo cabelo, nariz, até mesmo na roupa. Com esta dinâmica, reforçávamos a importância da higiene, não somente das mãos, mas também das roupas, das máscaras, dos calçados, da importância de manter as unhas curtas, entre outros aspectos. Explicamos também, devido a esse movimento propagador do "vírus", que não podíamos ainda nos abraçar ou tocar, porque, assim como o glitter que estava agora por todas as partes, o vírus também estaria, só que ele era invisível e isso demandava de um cuidado ainda maior de todos nós, porque é difícil nos protegermos do que não estamos vendo.

Figura 2: Experimentação com o glitter.

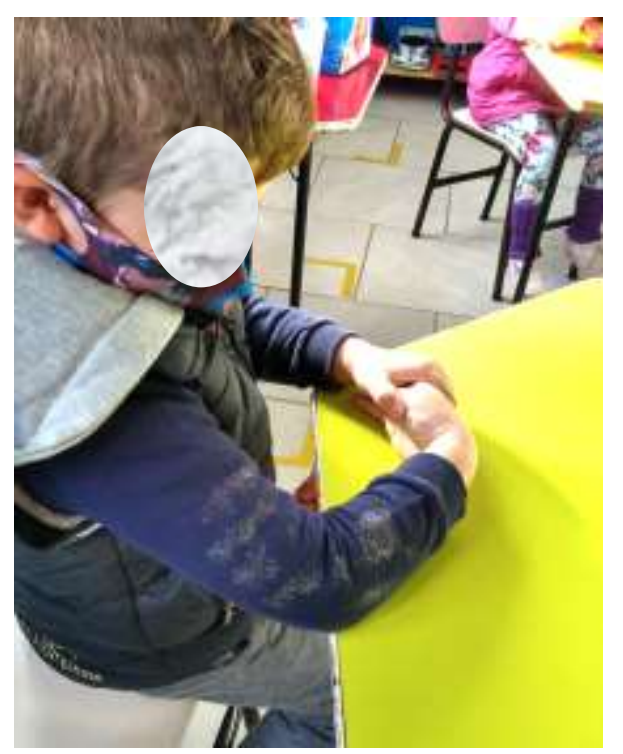

Fonte: Imagem do acervo das pesquisadoras (2021).

A supracitada experimentação foi um modo lúdico de trabalhar diferentes aspectos e elementos formativos importantes, como por exemplo: o respeito e cuidado consigo e com o próximo, questões de higiene pessoal e coletiva, a imaginação, a investigação exploratória. Sobretudo, acreditamos que exploramos uma estratégia educativa possível, de desenvolvimento acessível e, ao mesmo tempo, potente, para o trabalho com crianças e sua relação com a educação científica.

\subsection{Experimentação Dedo Mágico}

Para a experimentação do Dedo Mágico foi necessário como material um prato com água, orégano e detergente. Após colocar o orégano sobre a água, foi solicitado às crianças para que passassem detergente no dedo e o mergulhassem no prato com água e orégano. No instante em que isso é realizado, as folhas de orégano se afastam, deixando o centro do prato limpo (representando as partículas de sujeira, germes, bactérias e até mesmo o coronavírus). Ao produzir essa experimentação com as mãos das crianças, salientou-se a analogia de que, para estarmos seguros, é necessário lavar as mãos regularmente com sabão, fazendo os movimentos de fricção entre os dedos, nas palmas das mãos, nos polegares, embaixo das unhas e sobre o dorso da mão. 


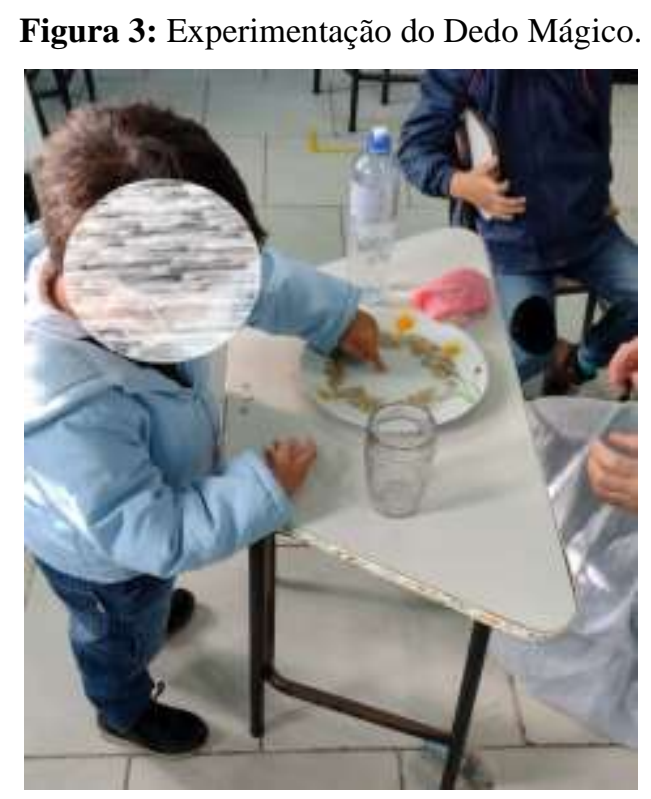

Fonte: Imagem do acervo das pesquisadoras (2021).

Na Educação Infantil observamos a importância do sensorial, do visível e da experimentação, elementos que foram contemplados diante desta experiência do Dedo Mágico, explorando as descobertas que estavam sendo feitas no presente momento, elucidando uma estratégia simples e aplicável com crianças.

Estávamos indo em direção a um dos direitos de aprendizagem promulgados pelo arquivo da BNCC (2018), explorando “[...] movimentos, gestos, sons, formas, texturas, cores, palavras, emoções, transformações, relacionamentos, histórias, objetos, elementos da natureza, na escola e fora dela, ampliando seus saberes sobre a cultura, em suas diversas modalidades: as artes, a escrita, a ciência e a tecnologia” (p. 38).

Destarte, tivemos o cuidado de, durante o processo e desenvolvimento das atividades, de fabricar um ambiente em que as crianças se sentissem envolvidas, apesar do distanciamento e das normas de biossegurança obrigatórias e rígidas. De que se sentissem seguras, num espaço descontraído e extrovertido e prezando pelo desenvolvimento pedagógico das mesmas. Desse modo, decidimos propor uma dança ao som da música "Lavar as Mãos (Mão)", da banda Palavra Cantada (composição de Arnaldo Antunes), a qual nos permitiu explorar aspectos corporais, motores, de expressão, movimento, junto à construção de hábitos de higiene, produzindo uma presença alegre, atenta e com direcionamento conceitual e pedagógico nos encontros que se davam com as crianças.

\subsection{Processo Avaliativo}

Como processo avaliativo dos encontros, identificando e analisando as construções desenvolvidas durante o mesmo, resolvemos propor duas atividades. Uma delas foi vendar os olhos das crianças e colocar um pouco de tinta guache na palma das mãos delas, em seguida solicitando que as mesmas simulassem a lavagem das mãos. Novamente, lançamos mão do estímulo à imaginação, nesse brincar do faz de conta, direcionando a pedido a elas: "Finjam que estão lavando as mãos... Como vocês fazem normalmente?" Para, então, conectarmos esse pedido ao conhecimento científico necessário de ser explorado, reiteramos para que as crianças aproveitassem e utilizassem todos os pontos de lavagem da mão, já exposto a elas anteriormente. Após elas externalizarem que haviam terminado, retiramos as vendas dos seus olhos e solicitamos para que juntas observassem se todas as áreas da mão estavam cobertas com a tinta guache. Esse gesto de visualização das áreas das mãos, se todas elas estavam com a tinta, veio ao encontro de reforçar e acrescentar que todos os movimentos realizados durante o "lavar as mãos" são necessários, frisando que as áreas não atingidas pela tinta não foram devidamente limpas. 
Como segundo movimento, para seguir promovendo um espaço onde as crianças poderiam externalizar os sentimentos que surgiram durante os encontros, foi disponibilizado a elas diferentes materiais (papel, giz de cera, lápis coloridos e formas geométricas de papelão) para que se expressassem da forma em que se sentissem mais à vontade, estimulando sua expressividade, sua autonomia e criação. Esta atividade foi inspirada pelo Guia de Orientações e sua proposta intitulada 'Acolher vidas para fortalecer emoções e criar estratégias pós-pandemia - COVID-19', material da Secretaria Nacional dos Direitos da Criança e do Adolescente no ano de 2020.

Figura 4: Processo Avaliativo.

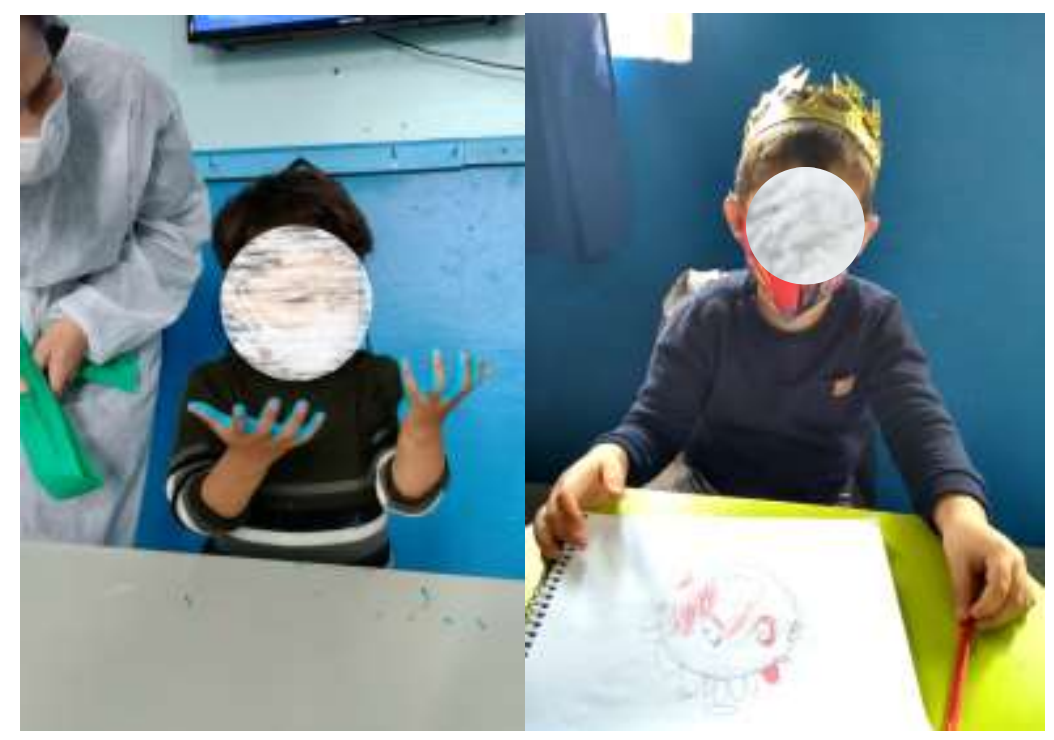

Fonte: Imagem do acervo das pesquisadoras (2021).

No Guia de Orientações sugere-se "Promover espaço de acolhimento e escuta dos sentimentos e das emoções por meio do desenho; e externalizar os sentimentos que surgem ao desenhar, pois uma das formas das crianças menores expressarem sentimentos e emoções acontece por meio do desenho" (Brasil, 2020, p. 25).

Nesse sentido, a escolha do desenho nessa estratégia de avaliação constitui-se enquanto um elo potente e importante para que as crianças possam colocar em movimento suas múltiplas formas de expressão, de dar vazão a sentimentos e emoções, indo ao encontro da constituição de um ambiente saudável e interessante para a alimentação da própria imaginação infantil. Acreditamos que isso permita flertar com um processo de aprendizagem calcado na ética da relação que uma criança estabelece consigo própria e com o outro, tendo em vista a construção de um território fértil para tal.

\section{Considerações Finais}

Com base na série de ações que foram implementadas no cerne da Educação Infantil de uma instituição de ensino do interior do Rio Grande do Sul, foi possível direcionar a atenção para a construção de subsídios diversificados e potentes para o retorno presencial da educação escolar com crianças, desenvolvimento conhecimentos inerentes à área das Ciências da Natureza.

Por intermédio das ações envolvendo aspectos dos Campos de Experiência da BNCC, alinhado às práticas e aos conhecimentos pertencentes à área das Ciências da Natureza - bem como os conhecimentos pedagógicos da professora regente, foi possível aguçar um gesto de escuta para as narrativas, perguntas, expressões das crianças, afinando um corpo presente e atento com suas elaborações pessoais relacionadas ao coronavírus e a pandemia, com vistas a produzir possibilidades de exploração pedagógica. 
Da mesma forma, pode-se vivenciar e pensar sobre a escola e, ao mesmo tempo, com a escola, em um momento problemático de sua existência no Brasil. Um movimento de parar, de estar em situação de isolamento social e, ao mesmo tempo, de reinventar modos de ocupar e existir na/com escola após os efeitos de uma pandemia global, e que infelizmente segue em curso. Um espaço-tempo de colocar em suspensão práticas de ensino e aprendizagem a que estávamos habituados (docentes e estudantes), criando vias outras para experimentar o aprender a agregar diferentes ações-verbos corporais e mentais com as crianças: explorar, observar, relatar, comunicar, reconhecer, participar, movimentar, imaginar, interagir, manifestar, expressar, criar, entre tantos outros (BNCC, 2018).

As crianças nos oferecem inesgotáveis acessos à potência inventiva e derivatória, colocando adultos a pensar, criar e ver novas formas de estar no mundo junto delas. Alinhar Ciências às condições usuais da vida que acontece no agora, no entorno, é exatamente o que as crianças nos permitem produzir, algo ainda pouco investido em termos de Educação Infantil no território educacional brasileiro. Portanto, com este estudo, acreditamos abrir vias e vontades de pesquisas futuras para continuarmos tensionando horizontes de experimentação e criação no âmbito da atuação pedagógica junto às crianças na Educação Infantil, principalmente no que tange a multiplicidade de saberes e conhecimentos inerentes a área de Ensino de Ciências da Natureza.

\section{Agradecimentos}

Agradecemos o acolhimento da instituição educativa aonde desenvolvemos as atividades apresentadas nessa pesquisa.

\section{Referências}

Brasil. (2018). Base Nacional Comum Curricular: Educação é a Base.

Brasil. (2020). Guia de orientações. Acolher vidas para fortalecer emoções e criar estratégias pós-pandemia - covid-19. Secretaria Nacional dos Direitos da Criança e do Adolescente.

Costin, C. (2020). Desafios da educação no Brasil após a Covid-2019. In Costin, C. et al. (Livro eletrônico). A escola na pandemia: 9 visões sobre a crise do ensino durante o coronavírus.

Creswell, J. W. (2007). Projeto de pesquisa: métodos qualitativo, quantitativo e misto. (2a ed.), Artmed.

Cruz, M. M. (2021). Meu nome é coronavírus, https://catve.com/arquivos/15840192955e6a375f71bfd.pdf

Dalmaso, A. C., Oliveira, M. O., \& Corrêa, G. C. (2018). Pergunta-criança: uma estratégia de aprender (e ensinar) Ciências. Revista Tempos e Espaços em Educação, 11(25), 213-226. https://doi.org/10.20952/revtee.v11i25.6921.

Dalmaso, A. C., Rigue, F. M. (2020). O convite da Atenção e seus efeitos em Educação: entre labirintos, feitiçarias e cuidados. In: Neuscharank, A., Halberstadt, I. A., Zanatta, J. M. Z. (Orgs.). Possibilidades... Aprendizagens, experiências e gestão na educação. Beau Bassin: Novas Edições Acadêmicas, $19-40$.

Dalmaso, A. C., \& Rigue, F. M. (2021). Entrelaçamentos educacionais: continuidade do viver e educação para a atenção. Research, Society and Development, 10 (14), e117101421831. https://doi.org/10.33448/rsd-v10i14.21831

Dalmaso, A. C., Oliveira, M. O., \& Rigue, F. M. (2021). O que pode a pergunta-criança na formação de professoras/es? Algumas experimentações teóricopráticas. Revista Quaestio, 23 (2), 321-339. http://dx.doi.org/10.22483/2177-5796.2021v23n2p321-339

Deleuze, G., Guattari, F. (1997). Mil Platôs: capitalismo e esquizofrenia. Ed. 34.

Goldenberg, M. (1997). A arte de pesquisar. Record.

Josso, M.-C. (2004). Experiências de vida e formação. Cortez.

Kastrup, V. 2000. O devir criança e a cognição contemporânea. Revista Psicologia: Reflexão e Crítica, 13(3), 373-382. http://dx.doi.org/10.1590/S0102-79722000000300006.

Maturana, H., \& Verden-Zoller, G. (2004). Amar e brincar: fundamentos esquecidos do humano. Palas Athena.

Manual do mundo (2014). Dedo mágico de orégano (experiência de química). https://www.youtube.com/watch?v=uOF9TXCXvQM

Rigue, F. M., Amestoy, M. B., \& Corrêa, G. C. (2019). Ensino de ciências e formação de professores: a criança e a alfabetização científica. Pesquisa, Sociedade e Desenvolvimento, 8 (10), 1-17, e348101390. https://doi.org/10.33448/rsd-v8i10.1390 
Research, Society and Development, v. 10, n. 16, e526101623901, 2021

(CC BY 4.0) | ISSN 2525-3409 | DOI: http://dx.doi.org/10.33448/rsd-v10i16.23901

Rigue, F. M. (2021). O acesso ao corpo mínimo e os processos educacionais: tomos-vacúolos de uma escrita oficina. In Rigue, F. M. Rizomas em Educação. Veranópolis: Editora Diálogo Freireano, 13-28.

Schérer, R. (2005). Aprender com Deleuze. Educação e Sociedade, 26(93), 1183-1194.

Siegel, D. J., \& Bryson, T. P. (2015). O cérebro da criança: 12 estratégias revolucionárias para nutrir a mente em desenvolvimento do seu filho e ajudar sua família a prosperar. nVersos.

Tripp, D. (2005). Pesquisa-ação: uma introdução metodológica. Educação e Pesquisa, 31(3), 443-466. 